Review Article

\title{
Emerging pathogenic mechanisms in human myxomatous mitral valve: lessons from past and novel data
}

\author{
Alexia Hulin ${ }^{a}$, Christophe Deroanne ${ }^{a}$, Charles Lambert ${ }^{a}$, Jean-Olivier Defraigne ${ }^{b}$, Betty Nusgens ${ }^{a, *}$, \\ Marc Radermecker ${ }^{\mathrm{c}, 1}$, Alain Colige ${ }^{\mathrm{a}, 1}$ \\ a Laboratory of Connective Tissues Biology, GIGA, University of Liège, Liège, Belgium \\ b Department of Cardiovascular and Thoracic Surgery, CHU Sart-Tilman, University of Liège, Belgium \\ c Department of Cardiovascular and Thoracic Surgery and Human Anatomy, CHU Sart-Tilman, University of Liège, Belgium
}

\section{A R T I C L E I N F O}

\section{Article history:}

Received 27 August 2012

Received in revised form 11 October 2012

Accepted 7 November 2012

\section{Keywords:}

Myxomatous mitral valve

Global transcriptomic analysis

Pathogenic mechanisms

\begin{abstract}
A B S T R A C T
Introduction: Myxomatous mitral valve is one of the most common heart valves diseases in human and has been well characterized at a functional and morphological level. Diseased valves are thickened as a result of extracellular matrix remodeling and proteoglycans accumulation accompanied by the disruption of the stratified structures of the leaflets.

Methods: Global transcriptomic analysis was used as a start-up to investigate potential pathogenic mechanisms involved in the development of the human idiopathic myxomatous mitral valve, which have been elusive for many years.

Results: These prospective analyses have highlighted the potential role of apparently unrelated molecules in myxomatous mitral valve such as members of the transforming growth factor- $\beta$ superfamily, aggrecanases of the "a disintegrin and metalloprotease with thrombospondin repeats I" family, and a weakening of the protection against oxidative stress. We have integrated, in this review, recent transcriptomic data from our laboratory [A. Hulin, C.F. Deroanne, C.A. Lambert, B. Dumont, V. Castronovo, J.O. Defraigne, et al. Metallothionein-dependent up-regulation of TGF-beta2 participates in the remodelling of the myxomatous mitral valve. Cardiovasc Res 2012;93:480-489] and from the publication of Sainger et al. [R. Sainger, J.B. Grau, E. Branchetti, P. Poggio, W.F. Seefried, B.C. Field, et al. Human myxomatous mitral valve prolapse: role of bone morphogenetic protein 4 in valvular interstitial cell activation. J Cell Physiol 2012;227:2595-2604] with existing literature and information issued from the study of monogenic syndromes and animal models. Conclusion: Understanding cellular alterations and molecular mechanisms involved in myxomatous mitral valve should help at identifying relevant targets for future effective pharmacological therapy to prevent or reduce its progression.
\end{abstract}

(c) 2013 Elsevier Inc. All rights reserved.

\section{Introduction}

Myxomatous mitral valve (MMV) is characterized by an altered architectural organization of the leaflets with disruption of the threelaminar stratification and abnormal accumulation of elastin and collagen that appear as fragmented and disorganized fibers. Another cardinal feature is an excessive deposition of poorly organized proteoglycans mainly in the spongiosa [3]. This extracellular matrix (ECM) remodeling progressively results in thickening of one or both leaflets, the posterior segment being the most frequently affected. They become floppy with excessive redundant tissue. As it is further

This work was supported by the Belgian "Fonds de la Recherche Scientifique" grant no. 1.1.159.08 and the Leon Fredericq Foundation from the University of Liège.

* Corresponding author. Laboratory of Connective Tissues Biology, University of Liège Tour de Pathologie, B23/3-B-4000 Sart Tilman, Belgium. Tel.: +32 4 3662456; fax: + 32 43662457.

E-mail address: betty.nusgens@ulg.ac.be (B. Nusgens).

${ }^{1}$ Equally promoted the work. coupled to a weakening or rupture of the chordae tendineae, this causes a prolapse of mitral leaflet(s) into the left atrium during systole, which progressively leads to an incomplete closure of the valve and, ultimately, to mitral regurgitation and cardiac insufficiency.

The prevalence of mitral valve prolapse is estimated at $2 \%$ to $3 \%$ of the general population and increases with age [4,5]. Although MMV disease is the most frequent cause of nonischemic mitral regurgitation in industrialized countries, effective pharmacological treatment preventing or reducing its progression is currently not available. This might be related to the sparsity of dedicated studies that address the cellular alterations and molecular mechanisms regulating the different phases of the myxomatous degeneration development and worsening [6]

Available data in the literature suggest that cells that reside within the valve, collectively called valvular interstitial cells (VICs), might be the key actors. VICs include cells displaying phenotypic features of fibroblasts, myofibroblasts, smooth muscle cells, and progenitors and exchange information with the endothelial layer covering the valvular 
Table 1

Selected data from microarray analysis of MMV and healthy mitral valve (control)

\begin{tabular}{|c|c|c|c|c|}
\hline \multirow[t]{2}{*}{ Gene } & & \multicolumn{3}{|c|}{$\begin{array}{l}\text { Fold change } \\
\text { (MMV vs. control) }\end{array}$} \\
\hline & & {$[1]^{\mathrm{a}}$} & {$\left[{ }^{*}\right]^{\mathrm{a}}$} & {$[2]^{a}$} \\
\hline CD34 & CD34 molecule & & 1.7 & \\
\hline \multicolumn{5}{|c|}{ Extracellular matrix } \\
\hline TGF- $\beta 2$ & Transforming growth factor beta 2 & 1.7 & & \\
\hline LTBP4 & $\begin{array}{l}\text { Latent transforming growth factor beta } \\
\text { binding protein } 4\end{array}$ & & 2.6 & 8.0 \\
\hline BMP4 & Bone morphogenetic protein 4 & & 2.3 & 8.0 \\
\hline SOX 9 & SRY (sex determining region Y)-box 9 & & 1.4 & 6.0 \\
\hline COMP & Cartilage oligomeric matrix protein & & & 6.7 \\
\hline CRTAC1 & Cartilage acidic protein 1 & & & 21 \\
\hline SPP1 & Osteopontin & & -3.3 & \\
\hline BGN & Biglycan & & & 4.1 \\
\hline $\mathrm{DCN}$ & Decorin & & & 2.1 \\
\hline VSCN & Versican & & & 3.0 \\
\hline XYLT-I & Xylosyltransferase I & & 1.6 & \\
\hline ADAMTS-1 & $\begin{array}{l}\text { ADAM metallopeptidase with } \\
\text { thrombospondin type } 1 \text { motif, } 1\end{array}$ & -2.5 & & \\
\hline ADAMTS-5 & $\begin{array}{l}\text { ADAM metallopeptidase with } \\
\text { thrombospondin type } 1 \text { motif, } 5\end{array}$ & -3.3 & & \\
\hline ADAMTS-9 & $\begin{array}{l}\text { ADAM metallopeptidase with } \\
\text { thrombospondin type } 1 \text { motif, } 9\end{array}$ & -2.0 & & \\
\hline \multicolumn{5}{|c|}{ Antioxidant system } \\
\hline MT1E & Metallothionein $1 \mathrm{E}$ & -3.2 & & \\
\hline MT1F & Metallothionein $1 \mathrm{~F}$ & -5.7 & & \\
\hline MT1G & Metallothionein 1G & -4.6 & & \\
\hline MT1M & Metallothionein $1 \mathrm{M}$ & -6.5 & & \\
\hline MT1P2 & Metallothionein 1 pseudogene 2 & -3.3 & & \\
\hline MT1X & Metallothionein $1 \mathrm{X}$ & -4.6 & & \\
\hline MT2A & Metallothionein 2A & -3.2 & & \\
\hline NQ01 & $\mathrm{NAD}(\mathrm{P}) \mathrm{H}$ dehydrogenase, quinone 1 & & -2.0 & \\
\hline SOD2 & Superoxide dismutase 2 & -4.9 & & \\
\hline GLRX & Glutaredoxin (thioltransferase) & -2.3 & & \\
\hline TXN & Thioredoxin & & -1.7 & \\
\hline \multicolumn{5}{|c|}{ Muscle proteins } \\
\hline MYH6 & $\begin{array}{l}\text { Myosin, heavy chain } 6 \text {, cardiac } \\
\text { muscle, alpha }\end{array}$ & & -1663 & \\
\hline MYH7 & $\begin{array}{l}\text { Myosin, heavy chain } 7 \text {, cardiac } \\
\text { muscle, beta }\end{array}$ & & -10.6 & \\
\hline TNNI3 & Troponin I type 3 (cardiac) & & -19.7 & \\
\hline TNNT2 & Troponin T type 2 (cardiac) & & -42 & \\
\hline TPM1 & Tropomyosin 1 (alpha) & & -8.6 & \\
\hline TPM2 & Tropomyosin 2 (beta) & & -2.5 & \\
\hline TPM3 & Tropomyosin 3 & & -2.1 & \\
\hline DES & Desmin & & -9.2 & \\
\hline SMTN & Smoothelin & & -1.6 & \\
\hline ACTA1 & Actin, alpha 1 , skeletal muscle & & -111 & \\
\hline ACTC1 & Actin, alpha, cardiac muscle 1 & & -45 & \\
\hline ACTG2 & Actin, gamma 2 , smooth muscle, enteric & & -32 & \\
\hline ACTN2 & Actinin, alpha 2 & & -64 & \\
\hline MYH11 & Myosin, heavy chain 11, smooth muscle & & -14 & \\
\hline MYL2 & $\begin{array}{l}\text { Myosin, light chain } 2 \text {, regulatory, } \\
\text { cardiac, slow }\end{array}$ & & -147 & \\
\hline MYL3 & $\begin{array}{l}\text { Myosin, light chain 3, ventricular, } \\
\text { skeletal, slow }\end{array}$ & & -4.9 & \\
\hline MYL4 & Myosin, light chain 4 , atrial, embryonic & & -17 & \\
\hline MYL7 & Myosin, light chain 7, regulatory & & -416 & \\
\hline MYL9 & Myosin, light chain 9 , regulatory & & -2.3 & \\
\hline MYLK & Myosin, light chain kinase & & -3.0 & \\
\hline CKM & Creatine kinase, muscle & & -85 & \\
\hline MYOM1 & Myomesin 1 & & -2.3 & \\
\hline MYOM2 & Myomesin 2 & & -3.0 & \\
\hline MYOZ1 & Myozenin 1 & & -3.0 & \\
\hline MYOZ2 & Myozenin 2 & & -4.0 & \\
\hline FLNC & Filamin C, gamma & & -3.2 & \\
\hline TAGLN & Transgelin & & -1.8 & \\
\hline NEBL & Nebulette & & -24 & \\
\hline \multicolumn{5}{|c|}{ Calcium binding proteins } \\
\hline CALM1 & Calmodulin 1 & & -1.6 & \\
\hline S100A8 & S100 calcium binding protein A8 & & -11 & \\
\hline S100A9 & S100 calcium binding protein A9 & & -4.3 & \\
\hline TNNC1 & Troponin C type 1 (slow) & & -74 & \\
\hline CNN1 & Calponin 1 , basic, smooth muscle & & -4.0 & \\
\hline
\end{tabular}

\begin{tabular}{|c|c|c|c|c|}
\hline \multirow[t]{2}{*}{ Gene } & & \multicolumn{3}{|c|}{$\begin{array}{l}\text { Fold change } \\
\text { (MMV vs. control) }\end{array}$} \\
\hline & & {$[1]^{\mathrm{a}}$} & {$\left[{ }^{*}\right]^{\mathrm{a}}$} & {$[2]^{\mathrm{a}}$} \\
\hline \multicolumn{5}{|c|}{ Calcium homeostasis } \\
\hline CASQ2 & Calsequestrin 2 (cardiac muscle) & & -416 & \\
\hline ATP2A2 & ATPase, $\mathrm{Ca}^{++}$transporting, cardiac muscle & & -2.6 & \\
\hline PLN & Phospholamban & & -315 & \\
\hline \multicolumn{5}{|c|}{ Endothelin receptor } \\
\hline EDNRA & Endothelin receptor type A & & -4.6 & \\
\hline \multicolumn{5}{|c|}{ Serotonin signaling } \\
\hline HT2AR & $\begin{array}{l}\text { 5-hydroxytryptamine (serotonin) } \\
\text { receptor } 2 \mathrm{~A}\end{array}$ & & 3.3 & \\
\hline TPH1 & Tryptophan hydroxylase 1 & & 3.0 & \\
\hline
\end{tabular}

a Selected data from a previous publication [1] and from the complete listing of regulated genes provided in the supplemental material $\left[{ }^{*}\right]$ and those published by Sainger et al. [2] obtained by microarray analysis comparing human P2 segment of posterior leaflet of MMVs and healthy P2 segments.

tissue. VICs are involved in the housekeeping of the valve leaflets and the turnover of the ECM to maintain their mechanical competence and function. Upon changes in the physical and/or chemical environments, VICs acquire features of activated myofibroblasts, proliferate, and produce increased amounts of collagens, proteoglycans, and MMPs, which are most likely responsible for the remodeling of collagen and elastic fibers [7]. Moreover, human MMV is also associated with the acquisition by valvular cells of a cartilaginous phenotype [8]. Until now, no molecular mechanism was proposed to explain this modification of the VIC phenotype. Recently, we [1] and another research group [2] used global transcriptomic analysis as a start-up to investigate potential pathogenic mechanisms in human idiopathic MMV. These prospective analyses have identified members of the transforming growth factor (TGF)- $\beta$ superfamily, "a disintegrin and metalloprotease with thrombospondin repeats I" (ADAMTS), and a weakening of the protection against oxidative stress as potential key phases in MMV. This article reviews the current knowledge about molecular mechanisms involved in MMV and exposes some promising perspectives in light of these results. A selection of genes regulated in MMV is detailed in Table 1. The complete list of up- and downregulated genes by a factor of $\geq 1.5$ is available as supplemental data online.

\section{TGF- $\beta$ superfamily}

In mammals, the TGF- $\beta$ superfamily comprises 33 members including the 3 archetypal TGF- $\beta$ isoforms (TGF- $\beta$ 1, 2, and 3 ) and 20 proteins of the bone morphogenetic subfamily (BMPs). All TGF- $\beta$ superfamily ligands elicit their cellular effects by binding to a complex of type II and type I serine/threonine kinase transmembrane receptors, sometimes in conjunction with either the type III receptor (TGFßR3/betaglycan) or endoglin acting as facilitating coreceptors. Five type II receptors and seven type I receptors, also termed activin receptor-like kinases (ALKs), are expressed in mammals. TGF- $\beta$ signals in most cells via TGF- $\beta$ receptor type II (TGFBRII) and ALK5, while BMPs signaling is mediated through BMP type II receptor (BMPRII) and ALK1, 2, 3, or 6. Upon TGF- $\beta$ binding and activation of its signaling receptor, Smad2 and 3 are phosphorylated, associate with Smad4, and translocate to the nucleus to operate transcriptional activity. The signaling of BMPs is mediated through phosphorylation of Smad1, 5, and 8 [9]. In addition of this canonical pathway, TGF- $\beta$ signals also through several Smad-independent cascades such as calcium-calcineurin and MAPK pathways. Two almost simultaneous transcriptomic studies comparing myxomatous and control mitral valves revealed, for the first time, an increased expression of TGF- $\beta 2$ [1] and BMP4 [2] in human MMV. Their significance in the mitral valve disease was further demonstrated by investigating the effect of these growth factors on VIC in vitro. 


\subsection{TGF- $\beta 2$}

The lesson learned from heritable connective tissue disorders was that MMV might be associated with a dysregulation of TGF- $\beta$ signaling. Indeed, MMV was observed in a few monogenic connective tissue disorders such as the Loeys-Dietz syndrome caused by excessive TGF- $\beta$ signaling resulting from activating mutations in TGFBRI or II [10]. Mutations in ADAMTSL2 cause a rare autosomal recessive disorder called geleophysic dysplasia. Affected patients present dilatation and thickening of heart valves, and the mutated fibroblasts are characterized by an increase in total and active TGF- $\beta 1$ [11]. Due to its interaction with LTBP1 and fibrillin-1 (fbn1), the molecular consequence of ADAMTSL2 mutation is an alteration of microfibrils which, in turn, interfere with TGF- $\beta$ sequestration [12]. Abnormal valves are also frequently observed in patients with Marfan syndrome. This dominant heritable disease is caused by mutations in fbn 1 gene, resulting as for geleophysic dysplasia in activation of TGF- $\beta$ signaling. MMV is also observed in homozygous and heterozygous mice with a fully expressed missense mutation in Fbn1 [13]. An efficient treatment of these mice was obtained with a TGF- $\beta$ neutralizing antibody [13] or with losartan, a selective angiotensin II type 1 receptor antagonist that interacts with TGF- $\beta$ signaling [14], further supporting the involvement of excessive TGF- $\beta$ signaling in MMV. With the exception of one single study showing a high expression of TGF- $\beta 1$ and TGF- $\beta 3$ in canine MMV [15], no study had shown so far an association between TGF- $\beta$ dysregulation and idiopathic MMV in humans.

We recently demonstrated that TGF- $\beta 2$ is expressed at a higher level in MMV (Table 1) and is also deposited, in some patients, in the valvular ECM. Most interestingly, TGF- $\beta 2$ level was correlated with the leaflet thickness, suggesting its implication during the progression of the disease [1]. An increased expression of LTBP-4, a protein forming and stabilizing latent TGF- $\beta$ complexes and acting as local regulators of TGF- $\beta$ activation [16], was also evidenced in MMV. Upon treatment with TGF- $\beta 2$, a significant percentage of VICs in culture acquired a myofibroblastic phenotype accompanied with an increased accumulation of versican, a constant feature of MMV tissues [1]. In light of this finding, it is worth noting that elevated TGF- 32 was reported in the mitral valves of fbn1-deficient mice [13] and the aorta of Marfan syndrome patients [17].

Valvulogenesis is initiated by an endothelial-mesenchymal transformation (EMT) that forms the endocardial cushions. These valvular primordia then further develop into mature structures through valve remodeling. Data collected using both in vitro and in vivo models show that TGF- $\beta 2$ is an important player in heart valve formation. It is highly expressed in cushion mesenchyme throughout valve development, whereas TGF- $\beta 3$ expression occurs only during the last stages and TGF- $\beta 1$ is weakly expressed [18]. Out of the three TGF- $\beta$ isoforms-deficient mice, only tgf- $\beta 2^{-1-}$ mice exhibited abnormal EMT and enlarged valves besides other congenital cardiovascular malformations. Collectively, these data indicate that TGF- $\beta 2$ is the major isoform that mediates EMT by regulating both its initiation and cessation stages $[19,20]$. Further analyses of the $\operatorname{tg} f-\beta 2^{-/-}$mice revealed that TGF- $\beta 2$ promotes also valve remodeling, is required for ECM organization, and represses the differentiation of the cushion mesenchyme into cartilage cell lineage during heart valve development. The remodeling cushions of $\operatorname{tg} f-\beta 2^{-1-}$ mice are notably characterized by a decreased expression of CD34, a marker expressed on most immature progenitors and stem cells of the hematopoietic system [21]. Its expression is modulated during differentiation, and progenitors gradually lose CD34 positivity when entering any specific differentiation lineage [22]. The positive regulation operated by TGF- $\beta 2$ on CD34 expression is suspected on the basis of the upregulation of $\mathrm{CD} 34$ by TGF- $\beta 1$ to maintain cells in an immature hematopoietic stage [23]. Interestingly, CD34 expression seems slightly higher in MMV tissues than in control samples (Table 1).
This needs to be confirmed on a larger number of patients but is consistent with a study reporting an increased density of CD34+ fibrocytes in human MMV [24]. In view of all these convergent data, it is clear that the relationship between TGF- $\beta 2$ and the differentiation of valvular cells in MMV would be worth to be further investigated.

\subsection{Bone morphogenetic proteins}

Recent studies have demonstrated the existence of shared or similar regulatory pathways operating during heart valve formation and development of cartilage, tendon, and even bone [25]. Pathologic processes that mimic osteogenesis and chondrogenesis have been observed, respectively, in degenerative aortic and mitral valve diseases [26]. These processes involve the low-density lipoprotein receptor-related protein 5 , an important receptor in the activation of bone formation by binding the secreted glycoprotein Wnt. MMV does not display a full osteoblastic phenotype but an early cartilage phenotype with positive Alcian blue staining and Sox9 expression [8]. This was further confirmed by Sainger et al. who showed an overexpression of Sox9 and the cartilaginous glycoproteins COMP and CRTAC1 in MMV (Table 1) [2]. As their microarray analyses highlighted an increased BMP4 expression in MMV, they suggest that BMP4 could be a major inducer of the phenotypic activation of VIC without osteogenic differentiation since osteogenic markers such as Runx2, osteopontin, and osterix were not modulated in MMV and not induced in BMP4-treated myxomatous VICs [2]. In agreement with these results, we showed a decreased expression of osteopontin (Spp1) (Table 1). This could be related to the increased expression of Sox9, a factor able to act as a transcriptional repressor of osteopontin expression and bone formation. Sox9 could therefore favor the cartilage phenotype characteristic of MMV [27]. Although an increased BMP2, BMP4, and BMP6 expression and phosphorylation of smad1, 5, and 8 have been reported in calcific aortic valve diseases $[28,29]$, this was the first time that BMPs were associated with human $\mathrm{MMV}$, a role that is reinforced by their up-regulation in the mouse model of Marfan [13].

Similarly to TGF- $\beta$, BMPs have been investigated during development and emerged as key factors in heart valve formation and morphogenesis [30,31]. BMP4 is important for the local proliferation and migration of cardiac neural crest cells and so for outflow tract valve development $[32,33]$. It does not seem to be required for the initiation of endocardial cushions formation, but it regulates the proliferation of atrioventricular cushion mesenchyme [34]. BMP2 appears as one of the major myocardium-derived inductive molecule able to regulate EMT, partly through the stimulation of TGF- 32 expression [35,36]. Surprisingly, however, periostin, which is a common target gene of TGF- $\beta$ and BMP, does not seem to be significantly altered in human MMV. This shows that the tissue context and the regulatory pathway operating in valves would deserve further characterizations.

\section{Proteoglycans and ADAMTS}

Versican, a major hyaluronan-binding proteoglycan playing a crucial role in the regulation of cardiovascular cells, and also biglycan and decorin are more abundant in myxomatous leaflets than in normal valves [3]. This accumulation could result from an increased synthesis as suggested by the higher expression of the core protein mRNA detected by Sainger et al. in their microarray analysis (Table 1) [2]. In agreement with this possibility, we showed indeed a slight increase of xylosyltransferase I (XYLT-I) (Table 1), the enzyme that initiates the binding of the first sugar residue of the polysaccharide side chain to the core protein. Surprisingly, however, we did not detect any significant increase in versican, biglycan, or decorin expression, suggesting that, at least in some conditions, the excessive accumulation of proteoglycans could also depend on a reduced degradation. 
This is a relevant alternative since we observed a decreased expression of ADAMTS-1, ADAMTS-4, ADAMTS-5, and ADAMTS-9 in MMV (Table 1) [1]. These ADAMTS are metalloproteinases belonging to the adamalysins family and function as proteoglycanases, one of their recognized substrate being versican. During development, ADAMTS-1 is expressed in the atrioventricular cushion and overlaps with versican and its cleavage product [37]. Alteration of versican proteolysis is at the origin of valvular development anomalies as suggested by the occurrence of MMV in mouse models of ADAMTS-5 deficiency and ADAMTS-9 haploinsufficiency [38,39]. Therefore, versican accumulation in the MMV spongiosa, as we and others showed [1,3], could result from its reduced degradation by aggrecanases.

In vitro treatment of VICs with TGF- $\beta 2$, which is increased in human MMV, results in a decreased ADAMTS-1 and ADAMTS-5 expression and an enhanced accumulation of versican, further suggesting a causal relationship between the activated TGF- $\beta 2$ signaling, the reduced ADAMTS- 1 and -5 levels, and the abundance of versican in human MMV tissues. In turn, it would be worth to evaluate the effect of reduced versican proteolysis on TGF- $\beta$ signaling as it was recently shown that increased pericellular versican in adamts $5^{-1-}$ fibroblasts affects the canonical TGF- $\beta$ signaling pathway and the fibroblast-myofibroblast transition [40].

\section{Oxidative stress}

Reactive oxygen species (ROS) include hydroxyl radicals, superoxide anion, hydrogen peroxide, and nitric oxide. They are produced during normal cellular function and are very transient species due to their high chemical reactivity that leads to lipid peroxidation and oxidation of DNA and proteins. When ROS generation is increased and overcomes the cellular antioxidant mechanisms, cells experience oxidative stress [41]. In MMV, several protective pathways seem to be altered as we noticed a decreased expression of $\mathrm{NAD}(\mathrm{P}) \mathrm{H}$ dehydrogenase quinone 1 (NQO1), superoxide dismutase 2 (SOD2), glutaredoxin (GLRX), thioredoxin (TXN) and metallothioneins (MTs) (Table 1). Antioxidant enzymes can either directly decompose ROS or facilitate the antioxidant reactions. NQO1 has an antioxidant role by catalyzing the reduction of quinone and by scavenging superoxide [42]. GLRX and TXN are small oxidoreductases structurally similar. Their antioxidant function is mediated via their redox-active thiol group [43]. SOD2 contains manganese in its active site and is located in the mitochondria. It converts free radical superoxide into peroxide. The reaction is mediated by successive oxidation and reduction of the transition metal ion at the active site [41]. MTs are small proteins rich in cysteine residues that confer antioxidant function [44]. They are involved in zinc homeostasis, but the full spectrum of their biological functions is not fully elucidated yet. Under hypoxia, oxidative stress, or metal exposure, MTs are transcriptionally activated upon nuclear translocation of the zinc finger factor MTF1 and its binding to the metal response elements present in their promoters [45].

A key feature of our study was the demonstration of a direct relationship between several different types of actors involved in MMV 1. By silencing the expression of MTs in VICs, an up-regulation of TGF- $\beta 2$, but not TGF- $\beta 1$ or -3 , was induced, which, in turn, may be responsible for the down-regulation of ADAMTS- 1 and -5 and the accumulation of versican as observed in human MMV. In agreement with these novel mechanisms, data from the literature show that a reduced expression of MTs caused by the loss of MTF1 is correlated to an increased expression and activation of TGF- $\beta 1$ and to an enhanced matrix deposition in tumors [46]. A low expression of MTs in the ascending aortic aneurysm in patients with bicuspid valve (BAV) is also thought to be associated with the remodeling of ECM [47]. Dysregulation of MTs expression is also expected to contribute to the inadequate response to oxidative stress observed in smooth muscle cells of BAV patients. Finally, increased oxidative stress resulting from alteration in the antioxidant mechanisms is reported in calcified regions of stenotic aortic valves [48]. Although the balance between ROS and the protective mechanisms was never directly evaluated in human MMV, it could be a major factor for maintaining the abnormal ECM in MMV.

\section{Muscle structural proteins and calcium homeostasis}

VICs have been shown to express a range of muscular structural proteins such as $\alpha$ - and $\beta$-myosin heavy chain (MYH6 and MYH7), for example. They express also skeletal and cardiac muscle components of the troponin complex (troponin T, I and C: TNNT, TNNI, and TNNC), as well as $\alpha$ and $\beta$ tropomyosins (TPM1 and TPM2) [51]. The presence of these muscle markers suggests that normal valve leaflets possess the required machinery for contractile response, which confirms a previous work showing that endothelin-1 can stimulate heart valve leaflet contraction $[49,50]$. In vivo, this mechanical function might participate in the maintenance of the leaflet tone. It could be due to the presence of contractile smooth muscle cells characterized by smoothelin expression at the atrialis side of mitral leaflets, especially in the anterior leaflets [52]. Our transcriptomic data indicate that mechanical function might be strongly impaired in MMV since a large number of proteins forming the structural and contractile apparatus, as well as desmin and smoothelin, are decreased (Table 1). Not only the structural and contractile proteins are down-regulated, but also calcium-binding proteins and proteins involved in the translocation of calcium between sarcoplasmic reticulum lumen and cytosol (Table 1). Finally, the decreased endothelin receptor type A (EDNRA) expression is another feature that could participate to the alteration of the mechanical function (Table 1). Whether these down-regulations are the cause or the consequence of the floppy movements of the leaflets and their prolapse remain to be understood, but they most probably explain part of the functional deficiency of affected valves.

\section{Serotonin signaling}

Serotonin (5-HT) is able to exert a wide variety of biological effects by interacting with specific membrane-bound receptors (HTRs). At least 13 distinct HTRs have been cloned and characterized. With the exception of the HTR3, which is a transmitter-gated ion, HTRs are members of the seven-transmembrane G-protein-coupled receptor superfamily [53]. In our MMV patients, the expression of HTR2A, the most functionally active of the HTR2, in cultured aortic VIC [54] and the expression of an enzyme involved in the synthesis of serotonin, tryptophan hydroxylase 1 (TPH1), were both increased in MMV (Table 1). This is in accordance with an increased concentration of TPH1 in canine and human MMVs [55] and the increased abundance of the HTR2B [56].

The hypothesis of an implication of 5-HT signaling in MMV is further strengthened by the occurrence of valvular heart disease in patients with elevated plasma 5-HT either upon administration of serotonergic drugs [57] or due to carcinoid heart disease [58,59]. The causal implication of serotonin was even more directly demonstrated by the occurrence of valvulopathies in rats chronically injected with serotonin [60]. Additional data obtained in a model of cultured sheep mitral valve indicate that 5-HT can be produced locally in the tissue in response to cyclic tensile strain and that it can regulate myofibroblastic activation and glycosaminoglycans synthesis [61]. It was further demonstrated that 5-HT was able to induce an up-regulation of TGF- 31 in valvular interstitial cells in vitro via G-protein signaling pathway [62].

\section{Conclusions}

The occurence of MMV in patients with heritable connective tissue disorders and the use of transgenic mouse models have allowed the identification of key genes for valve development, homeostasis, and function. Despite these advances, the mechanisms leading to the 
idiopathic form of MMVs are still poorly understood. Two global transcriptomic analyses were recently performed comparing healthy and diseased tissues. Members of the TGF- $\beta$ superfamily were identified as likely central actors in MMV, which would reflect the pathological mechanisms altering valves in Marfan and Loeys-Dietz syndromes. It has to be noticed however that these two independent studies pointed to two different, although related, factors TGF- $\beta 2$ and BMP4 that were increased in the two transcriptomic analyses. The implication of different factors of the same family and the expected induced regulation of similar, but not identical, signaling pathways would partly account for the phenotypic variations observed in patients with idiopathic MMVs. A major contribution of our study was the identification of a potential direct relationship between pathways that are altered in MMV, although they originally seemed to be independent from each other: oxidative stress, TGF- $\beta$ signaling, ADAMTS repression, and versican accumulation. The loss of expression of muscle contractile protein in MMV is also a noteworthy observation. Future studies will be required to determine whether all these modifications are the causes or the consequences of a primary and still unidentified defect. Furthermore, a modulation of these pathways by mechanical stimuli is most likely and should be considered in future studies. It is clear however that these studies bring new perspectives and improve the understanding of the pathogenic mechanisms in MMV that should help in identifying relevant targets for future effective pharmacological treatments.

Supplementary data to this article can be found online at http://dx. doi.org/10.1016/j.carpath.2012.11.001.

\section{Acknowledgments}

We acknowledge the technical assistance of the genomic platform from GIGA for microarray analyses.

\section{References}

[1] Hulin A, Deroanne CF, Lambert CA, Dumont B, Castronovo V, Defraigne JO, et al. Metallothionein-dependent up-regulation of TGF-beta2 participates in the remodelling of the myxomatous mitral valve. Cardiovasc Res 2012;93:480-9.

[2] Sainger R, Grau JB, Branchetti E, Poggio P, Seefried WF, Field BC, et al. Human myxomatous mitral valve prolapse: role of bone morphogenetic protein 4 in valvular interstitial cell activation. J Cell Physiol 2012;227:2595-604.

[3] Gupta V, Barzilla JE, Mendez JS, Stephens EH, Lee EL, Collard CD, et al. Abundance and location of proteoglycans and hyaluronan within normal and myxomatous mitral valves. Cardiovasc Pathol 2009;18:191-7.

[4] Freed LA, Levy D, Levine RA, Larson MG, Evans JC, Fuller DL, et al. Prevalence and clinical outcome of mitral-valve prolapse. N Engl J Med 1999;341:1-7.

[5] d'Arcy JL, Prendergast BD, Chambers JB, Ray SG, Bridgewater B. Valvular heart disease: the next cardiac epidemic. Heart 2011;97:91-3.

[6] Salhiyyah K, Yacoub MH, Chester AH. Cellular mechanisms in mitral valve disease. J Cardiovasc Transl Res 2011:4:702-9.

[7] Rabkin E, Aikawa M, Stone JR, Fukumoto Y, Libby P, Schoen FJ. Activated interstitial myofibroblasts express catabolic enzymes and mediate matrix remodeling in myxomatous heart valves. Circulation 2001;104:2525-32.

[8] Caira FC, Stock SR, Gleason TG, McGee EC, Huang J, Bonow RO, et al. Human degenerative valve disease is associated with up-regulation of low-density lipoprotein receptor-related protein 5 receptor-mediated bone formation. J Am Coll Cardiol 2006:47:1707-12.

[9] Goumans MJ, Liu Z, ten Dijke P. TGF-beta signaling in vascular biology and dysfunction. Cell Res 2009;19:116-27.

[10] Judge DP, Rouf R, Habashi J, Dietz HC. Mitral valve disease in marfan syndrome and related disorders. J Cardiovasc Transl Res 2011;4:741-7.

[11] Le Goff C, Morice-Picard F, Dagoneau N, Wang LW, Perrot C, Crow YJ, et al. ADAMTSL2 mutations in geleophysic dysplasia demonstrate a role for ADAMTSlike proteins in TGF-beta bioavailability regulation. Nat Genet 2008;40:1119-23.

[12] Le Goff C, Cormier-Daire V. The ADAMTS(L) family and human genetic disorders. Hum Mol Genet 2011;20:R163-7.

[13] Ng CM, Cheng A, Myers LA, Martinez-Murillo F, Jie C, Bedja D, et al. TGF-betadependent pathogenesis of mitral valve prolapse in a mouse model of Marfan syndrome. J Clin Invest 2004;114:1586-92.

[14] Habashi JP, Judge DP, Holm TM, Cohn RD, Loeys BL, Cooper TK, et al. Losartan, an AT1 antagonist, prevents aortic aneurysm in a mouse model of Marfan syndrome. Science 2006;312:117-21.

[15] Aupperle H, Marz I, Thielebein J, Schoon HA. Expression of transforming growth factor-beta1, -beta2 and -beta3 in normal and diseased canine mitral valves. J Comp Pathol 2008;139:97-107.
[16] Hyytiainen M, Penttinen C, Keski-Oja J. Latent TGF-beta binding proteins: extracellular matrix association and roles in TGF-beta activation. Crit Rev Clin Lab Sci 2004;41:233-64.

[17] Nataatmadja M, West J, West M. Overexpression of transforming growth factorbeta is associated with increased hyaluronan content and impairment of repair in Marfan syndrome aortic aneurysm. Circulation 2006;114:I371-7.

[18] Camenisch TD, Molin DG, Person A, Runyan RB, Gittenberger-de Groot AC, McDonald JA, et al. Temporal and distinct TGFbeta ligand requirements during mouse and avian endocardial cushion morphogenesis. Dev Biol 2002;248:170-81.

[19] Sanford LP, Ormsby I, Gittenberger-de Groot AC, Sariola H, Friedman R, Boivin GP, et al. TGFbeta2 knockout mice have multiple developmental defects that are nonoverlapping with other TGFbeta knockout phenotypes. Development 1997;124: 2659-70.

[20] Azhar M, Runyan RB, Gard C, Sanford LP, Miller ML, Andringa A, et al. Ligandspecific function of transforming growth factor beta in epithelial-mesenchymal transition in heart development. Dev Dyn 2009;238:431-42.

[21] Azhar M, Brown K, Gard C, Chen H, Rajan S, Elliott DA, et al. Transforming growth factor beta 2 is required for valve remodeling during heart development. Dev Dyn 2011:240:2127-41.

[22] Krause DS, Fackler MJ, Civin CI, May WS. CD34: structure, biology, and clinical utility. Blood 1996;87:1-13.

[23] Pierelli L, Marone M, Bonanno G, Rutella S, de Ritis D, Mancuso S, et al. Transforming growth factor-beta1 causes transcriptional activation of CD34 and preserves haematopoietic stem/progenitor cell activity. Br J Haematol 2002;118: 627-37.

[24] Barth PJ, Koster H, Moosdorf R. CD34+ fibrocytes in normal mitral valves and myxomatous mitral valve degeneration. Pathol Res Pract 2005;201:301-4.

[25] Lincoln J, Lange AW, Yutzey KE. Hearts and bones: shared regulatory mechanisms in heart valve, cartilage, tendon, and bone development. Dev Biol 2006;294: 292-302.

[26] Loardi C, Alamanni F, Trezzi M, Kassem S, Cavallotti L, Tremoli E, et al. Biology of mitral valve prolapse: the harvest is big, but the workers are few. Int J Cardiol 2011;151:129-35.

[27] Peacock JD, Huk DJ, Ediriweera HN, Lincoln J. Sox9 transcriptionally represses Spp 1 to prevent matrix mineralization in maturing heart valves and chondrocytes. PLoS One 2011;6:e26769.

[28] Mohler ER, Gannon F, Reynolds C, Zimmerman R, Keane MG, Kaplan FS. Bone formation and inflammation in cardiac valves. Circulation 2001;103:1522-8.

[29] Ankeny RF, Thourani VH, Weiss D, Vega JD, Taylor WR, Nerem RM, et al. Preferential activation of SMAD1/5/8 on the fibrosa endothelium in calcified human aortic valves-association with low BMP antagonists and SMAD6. PLoS One 2011;6:e20969.

[30] Yamagishi T, Ando K, Nakamura H. Roles of TGFbeta and BMP during valvuloseptal endocardial cushion formation. Anat Sci Int 2009;84:77-87.

[31] Conway SJ, Doetschman T, Azhar M. The inter-relationship of periostin, TGF beta, and BMP in heart valve development and valvular heart diseases. Scientific World Journal 2011:11:1509-24.

[32] Liu W, Selever J, Wang D, Lu MF, Moses KA, Schwartz RJ, et al. Bmp4 signaling is required for outflow-tract septation and branchial-arch artery remodeling. Proc Natl Acad Sci U S A 2004;101:4489-94.

[33] McCulley DJ, Kang JO, Martin JF, Black BL. BMP4 is required in the anterior heart field and its derivatives for endocardial cushion remodeling, outflow tract septation, and semilunar valve development. Dev Dyn 2008;237:3200-9.

[34] Jiao K, Kulessa H, Tompkins K, Zhou Y, Batts L, Baldwin HS, et al. An essential role of Bmp4 in the atrioventricular septation of the mouse heart. Genes Dev 2003;17: 2362-7

[35] Ma L, Lu MF, Schwartz RJ, Martin JF. Bmp2 is essential for cardiac cushion epithelial-mesenchymal transition and myocardial patterning. Development 2005;132:5601-11.

[36] Sugi Y, Yamamura H, Okagawa H, Markwald RR. Bone morphogenetic protein-2 can mediate myocardial regulation of atrioventricular cushion mesenchymal cell formation in mice. Dev Biol 2004;269:505-18.

[37] Kern CB, Twal WO, Mjaatvedt CH, Fairey SE, Toole BP, Iruela-Arispe ML, et al. Proteolytic cleavage of versican during cardiac cushion morphogenesis. Dev Dyn 2006;235:2238-47.

[38] Dupuis LE, McCulloch DR, McGarity JD, Bahan A, Wessels A, Weber D, et al. Altered versican cleavage in ADAMTS5 deficient mice; a novel etiology of myxomatous valve disease. Dev Biol 2011;357:152-64.

[39] Kern CB, Wessels A, McGarity J, Dixon LJ, Alston E, Argraves WS, et al. Reduced versican cleavage due to Adamts9 haploinsufficiency is associated with cardiac and aortic anomalies. Matrix Biol 2010;29:304-16.

[40] Hattori N, Carrino DA, Lauer ME, Vasanji A, Wylie JD, Nelson CM, et al. Pericellular versican regulates the fibroblast-myofibroblast transition: a role for ADAMTS5 protease-mediated proteolysis. J Biol Chem 2011;286:34298-310.

[41] Mates JM. Effects of antioxidant enzymes in the molecular control of reactive oxygen species toxicology. Toxicology 2000;153:83-104.

[42] Dinkova-Kostova AT, Talalay P. NAD (P)H:quinone acceptor oxidoreductase 1 (NQO1), a multifunctional antioxidant enzyme and exceptionally versatile cytoprotector. Arch Biochem Biophys 2010;501:116-23.

[43] Oh YK, Lee TB, Choi CH. Anti-oxidant adaptation in the AML cells supersensitive to hydrogen peroxide. Biochem Biophys Res Commun 2004;319:41-5.

[44] Xue W, Liu Q, Cai L, Wang Z, Feng W. Stable overexpression of human metallothionein-IIA in a heart-derived cell line confers oxidative protection. Toxicol Lett 2009;188:70-6.

[45] Sutherland DE, Stillman MJ. The "magic numbers" of metallothionein. Metallomics 2011;3:444-63. 
[46] Haroon ZA, Amin K, Lichtlen P, Sato B, Huynh NT, Wang Z, et al. Loss of metal transcription factor-1 suppresses tumor growth through enhanced matrix deposition. FASEB J 2004;18:1176-84.

[47] Phillippi JA, Klyachko EA, JPt Kenny, Eskay MA, Gorman RC, Gleason TG. Basal and oxidative stress-induced expression of metallothionein is decreased in ascending aortic aneurysms of bicuspid aortic valve patients. Circulation 2009;119: 2498-506.

[48] Miller JD, Chu Y, Brooks RM, Richenbacher WE, Pena-Silva R, Heistad DD. Dysregulation of antioxidant mechanisms contributes to increased oxidative stress in calcific aortic valvular stenosis in humans. J Am Coll Cardiol 2008;52: 843-50.

[49] Brand NJ, Roy A, Hoare G, Chester A, Yacoub MH. Cultured interstitial cells from human heart valves express both specific skeletal muscle and non-muscle markers. Int J Biochem Cell Biol 2006;38:30-42.

[50] Chester AH, Taylor PM. Molecular and functional characteristics of heart-valve interstitial cells. Philos Trans R Soc Lond B Biol Sci 2007;362:1437-43.

[51] Roy A, Brand NJ, Yacoub MH. Molecular characterization of interstitial cells isolated from human heart valves. J Heart Valve Dis 2000;9:459-64.

[52] Cimini M, Rogers KA, Boughner DR. Smoothelin-positive cells in human and porcine semilunar valves. Histochem Cell Biol 2003;120:307-17.

[53] Hoyer D, Hannon JP, Martin GR. Molecular, pharmacological and functional diversity of 5-HT receptors. Pharmacol Biochem Behav 2002;71:533-54.

[54] Xu J, Jian B, Chu R, Lu Z, Li Q, Dunlop J, et al. Serotonin mechanisms in heart valve disease II: the 5-HT2 receptor and its signaling pathway in aortic valve interstitial cells. Am J Pathol 2002;161:2209-18.
[55] Disatian S, Lacerda C, Orton EC. Tryptophan hydroxylase 1 expression is increased in phenotype-altered canine and human degenerative myxomatous mitral valves. J Heart Valve Dis 2010;19:71-8.

[56] Disatian S, Orton EC. Autocrine serotonin and transforming growth factor beta 1 signaling mediates spontaneous myxomatous mitral valve disease. J Heart Valve Dis 2009;18:44-51.

[57] Rothman RB, Baumann MH. Serotonergic drugs and valvular heart disease. Expert Opin Drug Saf 2009;8:317-29.

[58] Hutcheson JD, Setola V, Roth BL, Merryman WD. Serotonin receptors and heart valve disease-it was meant 2B. Pharmacol Ther 2011;132:146-57.

[59] Robiolio PA, Rigolin VH, Wilson JS, Harrison JK, Sanders LL, Bashore TM, et al. Carcinoid heart disease. Correlation of high serotonin levels with valvular abnormalities detected by cardiac catheterization and echocardiography. Circulation 1995;92:790-5.

[60] Gustafsson BI, Tommeras K, Nordrum I, Loennechen JP, Brunsvik A, Solligard E, et al. Long-term serotonin administration induces heart valve disease in rats. Circulation 2005;111:1517-22.

[61] Lacerda CM, Kisiday J, Johnson B, Orton EC. Local serotonin mediates cyclic straininduced phenotype transformation, matrix degradation, and glycosaminoglycan synthesis in cultured sheep mitral valves. Am J Physiol Heart Circ Physiol 2012;302(10):H1983-90.

[62] Jian B, Xu J, Connolly J, Savani RC, Narula N, Liang B, Levy RJ. Serotonin mechanisms in heart valve disease I: serotonin-induced up-regulation of transforming growth facto-beta1 via G-protein signal transduction in aortic valve interstitial cells. Am J Pathol 2002;161(6):2111-21. 